\section{Cobalt-catalysed dimerization of styrenes under syngas ${ }^{\dagger}$}

M. Fontaine ${ }^{a}$, A.J. Hubert ${ }^{a}$, A.F. Noels ${ }^{\star, b}$, A. Demonceau ${ }^{b}$ and P. Teyssié ${ }^{\mathrm{b}}$

${ }^{a}$ Laboratory of Organic Synthesis and Catalysis, and ${ }^{b}$ Laboratory of Macromolecular Chemistry and Organic Catalysis, University of Liège, Sart Tilman (B.6), B-4000 Liège (Belgium)

(Received February 4th, 1991)

\section{Abstract}

Under a pressure of synthesis gas, cobalt carbonyl in pyridine catalyses the dimerization of styrene to yield 1,3-diphenylbutane selectively

Rather surprisingly, reports on catalysed dimerization of styrene are very few, although transition metal derivatives are widely used to catalyse the coupling of a variety of olefins [1]. (Before 1970, only mineral acids were used [2].) The first transition metal complexes found to dimerize styrene [3] (usually in low yield and with poor selectivity) were based on palladium. Later, nickel- and zirconium-based systems were also found to promote the dimerization [4]. We now report a new catalytic procedure for dimerization of styrene and its derivatives. Yields are relatively modest but the selectivity is high. The procedure is close to that we recently reported for the catalysed coupling of aldehydes to ketones [5].

In a typical experiment, styrene $(20 \mathrm{mmol})$ and dicobaltoctacarbonyl $(0.96 \mathrm{mmol})$ were dissolved in dry pyridine $(10 \mathrm{ml})$ in a Pyrex-glass lined stainless steel autoclave. Syngas was then introduced $\left(10 \mathrm{MPa} ; \mathrm{CO}: \mathrm{H}_{2}=4: 1\right)$ and the mixture heated for 12 $h$ at $140^{\circ} \mathrm{C}$. After venting and work-up, 1,3-diphenylbutane was identified as the main product (yield 43\%) [6*] with 1,3-diphenyl-1-butene, ethylbenzene, and some higher oligomers as byproducts. Blank experiments revealed the importance of using both pyridine as solvent and dicobaltoctacarbonyl as catalyst. Moreover, the tota pressure as well as the syngas composition influenced the outcome of the reaction. Indeed, as can be seen from Fig. 1, when the ratio of $\mathrm{CO} / \mathrm{H}_{2}$ decreased, the yield of 1,3-diphenylbutane fell. When the reaction vessel was pressurized with pure carbon monoxide (10 $\mathrm{MPa}$; no hydrogen), no saturated dimer was formed, but 1,3-diphenyl-1-butene was isolated in $30 \%$ yield $(E: Z=9: 1)$. By contrast, under a pressure of pure hydrogen (10 $\mathrm{MPa}$, no carbon monoxide, same conditions), styrene was reduced to ethylbenzene, whereas replacement of syngas by nitrogen favoured

${ }^{\dagger}$ Dedicated to the memory of Professor Piero Pino.

* Reference number with asterisk indicates a note in the list of references.

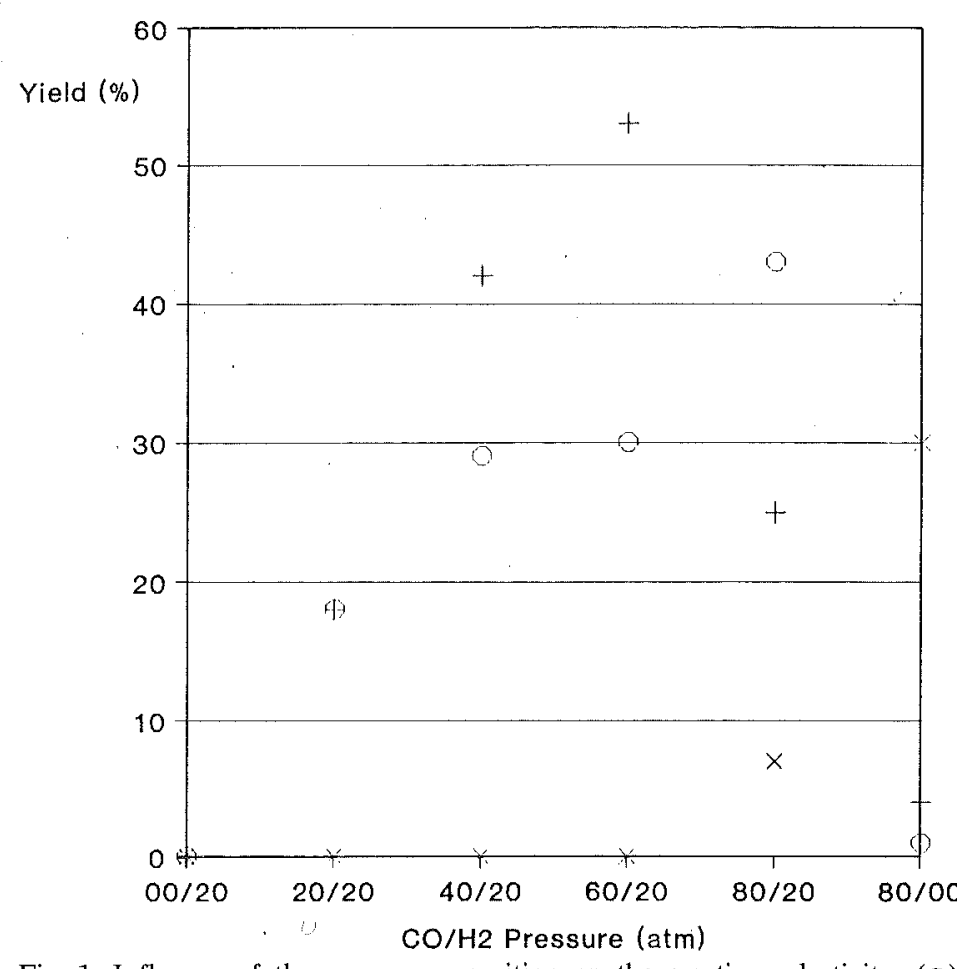

Fig. 1. Influence of the syngas composition on the reaction selectivity: (O) 1,3-diphenylbutane; $(+)$ ethylbenzene; $(\times)$ 1,3-diphenyl-1-butene.

the formation of styrene oligomers $\left(M_{\mathrm{n}}=6000, \Delta=2.4\right)$, GLC of which revealed a bimodal distribution. Under atmospheric pressure (of air or nitrogen) ca. $70 \%$ of styrene was recovered, the remainder being oligomerized.

The use of pyridine as solvent greatly enhances the catalytic activity of $\mathrm{Co}_{2}(\mathrm{CO})_{8}$ as we confirmed by trying various solvents and finding that none of them had the same effect as pyridine (see Table 1). Surprisingly, with 4-picoline as solvent dimerization was strongly disfavoured, which may reflect either subtle solvation

Table 1

Influence of solvent on the yield of 1,3-diphenylbutane

\begin{tabular}{lcclcc}
\hline Solvent & $\mathrm{p} K_{\mathrm{a}}$ & $\begin{array}{l}\text { Yield }^{b} \\
(\%)\end{array}$ & Solvent & $\mathrm{P} K_{\mathrm{a}}$ & $\begin{array}{l}\text { Yield }^{b} \\
(\%)\end{array}$ \\
\hline Pyridine & 5.25 & 43 & Dimethylaniline & 5.07 & $<2$ \\
4-Picoline & 6.03 & 7 & Nitrobenzene & 3.98 & 0 \\
3-Picoline & 5.63 & 21 & Acetonitrile & & 4 \\
2-Picoline & 5.94 & 30 & Dimethylformamide & & 4 \\
2,6-Lutidine & 6.60 & 13 & Triethylamine & 10.75 & $<1$ \\
2-Chloropyridine & 0.49 & 3 & Dioxane & & 3 \\
Piperidine & 11.12 & 0 & Benzene & & 3
\end{tabular}

Pa $\left(\mathrm{CO}: \mathrm{H}_{2}=4: 1\right), \mathrm{Co}_{2}(\mathrm{CO})_{8} 0.96 \mathrm{mmol}, 10$

${ }^{a}$ Reaction conditions: styrene $20 \mathrm{mmol}, P\left(\mathrm{CO}-\mathrm{H}_{2}\right) 10 \mathrm{MPa}\left(\mathrm{CO}: \mathrm{H}_{2}=4: 1\right), \mathrm{Co}_{2}(\mathrm{CO})_{8}$
ml solvent, heating time $12 \mathrm{~h}, T 140^{\circ} \mathrm{C}$. ${ }^{b}$ The yields were determined by $\mathrm{GLC}$ analysi 
Table 2

Yields of 1,3-diphenylbutane obtained with various metal carbonyls ${ }^{a}$

\begin{tabular}{lllc}
\hline Catalysts & $\begin{array}{l}\text { Yield }^{b} \\
(\%)\end{array}$ & Catalysts & $\begin{array}{l}\text { Yield }^{b} \\
(\%)\end{array}$ \\
\hline $\mathrm{CO}_{2}(\mathrm{CO})_{8}$ & 43 & $\mathrm{Ru}_{3}(\mathrm{CO})_{12} c$ & 0 \\
$\mathrm{Cr}(\mathrm{CO})_{6}$ & 0 & $\mathrm{Rh}_{6}(\mathrm{CO})_{16}{ }^{c}$ & 0 \\
$\mathrm{Mo}(\mathrm{CO})_{6}$ & 0 & $\mathrm{Fe}(\mathrm{CO})_{5}$ & 0 \\
$\mathrm{~W}(\mathrm{CO})_{6}$ & 0 & $\mathrm{Mn}_{2}(\mathrm{CO})_{10}$ & 19 \\
\hline
\end{tabular}

$\overline{a, b}$ Conditions as for Table $1 .{ }^{c} \mathrm{Ru}_{3}(\mathrm{CO})_{12}$ and $\mathrm{Rh}_{6}(\mathrm{CO})_{16} 0.025 \mathrm{mmol}$.

Table 3

Yields of dimers from styrene derivatives ${ }^{a}$

\begin{tabular}{llll}
\hline Substrates & $\begin{array}{l}\text { Yield }^{b} \\
(\%)\end{array}$ & Substrates & $\begin{array}{l}\text { Yield }^{b} \\
(\%)\end{array}$ \\
\hline$p$-MeStyrene & 39 & $p$-ClStyrene & 10 \\
$p-{ }^{t}$ BuStyrene & 39 & $o$-ClStyrene & 6 \\
$p$-MeOStyrene & 17 & $p$-BrStyrene & 0 \\
$o$-MeOStyrene & 9 & $\alpha$-MeStyrene & 13 \\
\hline
\end{tabular}

$\overline{a, b}$ Conditions as for Table 1 .

effects or a marked influence of the $\mathrm{p} K_{\mathrm{a}}$ of the ligand (compare the result with that for 2-picoline and for $N, N$-dimethylaniline, which have roughly similar $\mathrm{p} K_{\mathrm{a}} \mathrm{s}$ as pyridine).

A variety of metal carbonyls (Table 2) were tried but without success. In those experiments a large proportion of the styrene was usually recovered together with some higher oligomers $(<5 \%)$, except when ruthenium and rhodium carbonyls were used, then hydroformylation reactions took over.

Another important parameter is the reaction temperature; no 1,3-diphenylbutane was formed below $100^{\circ} \mathrm{C}$ and its yield decreased above $150^{\circ} \mathrm{C}$.

The reaction was extended to styrene derivatives and Table 3 presents some preliminary results. It is evident that the yields of dimers strongly depend on the nature and position of the substituent.

Further work is being carried out to assess the scope of the reaction and gain insight into the reaction mechanism.

Acknowledgement. We thank Professor W. Keim for mass spectrometric facilities. Support by Fonds National de la Recherche Scientifique, Brussels, for the purchase of major intrumentation is gratefully acknowledged.

\section{References and notes}

1 (a) H. Yasuda and Nakamura, Rew. Chem. Intermed., 6 (1986) 365 and references therein; (b) J.P. Collman, L.S. Hegedus, J.R. Norton and R.G. Finke, Principles and applications of Organotransition Metal Chemistruniversity Science Books, Mill Valley, CA, 1987.

2 (a) J. Rosen, J. Org. Chem., 18 (1953) 1701; (b) R.M. Parkhurst, J.O. Todin and R.M. Silverstein, J. Org Chem. 28 (1963) 120; (c) I.C. Calder, W.Y. Lee and F.E. Treloar, Austr. J. Chem., 22 (1969) 2689.
3 M.G. Barlow, M.J. Bryant, R.N. Haszeldine and A.G. Mackie, J. Organomet. Chem., 21 (1970) 215. 4 (a) F. Dawans, Tetrahedron Lett., 22 (1971) 1943; (b) P. Grenouillet, D. Neibecker and I. Tkatchenko, Organometalics, 3 (1984) 1130; (c) P. Barthelemy, A. Deffieux and P. Sigwalt, Nouv. J. Chim., (1985) 173.

5 M. Fontaine, A.F. Noels, A. Demonceau and A.J. Hubert, Tetrahedron Lett 31 (1990) 3117

6 All compounds were identified by GC-MS, GC-FTIR and comparison with authentic samples. 